\title{
PERENCANAAN STRATEGIK SISTEM DAN TEKNOLOGI INFORMASI PADA SEKOLAH DASAR ISLAM ALFAUZIEN DEPOK MENGGUNAKAN METODE WARD \& PEPPARD
}

\author{
JULIZAL \\ PUPUT IRFANSYAH \\ Program Studi Informatika \\ Fakultas Teknik, dan Ilmu Komputer \\ Universitas Indraprasta PGRI \\ Jl. Nangka No. 58 C, Tanjung Barat, Jagakarsa, Jakarta Selatan 12530 \\ Email: julizal.ram@gmail.com, irfandot@gmail.com
}

\begin{abstract}
Islamic Elementary School (SD Islam) is one part of the educational environment in which to do training and development of students toward the achievement of educational goals. Therefore, the implementation must have a plan which redirected, clear objectives and implementation of reliable. "Strategic Planning Systems and Information Technology at the Islamic Elementary School Alfauzien Depok environment", as seen from the performance in an effort to use IT to solve the various problems the school environment is not optimal, An example of the use of SI and IT in the processing of special processing automatic and centralized data management, utilization of the ti to integrate information across school, SD Islam Alfauzien still do not have the IT infrastructure to support an integrated information exchange between schools in Depok, Utilization of SI and strategic use of IT as a whole school led to less in Depok have not felt the function of the SI \& IT strategic, such as data processing and adoption of new students to serve the public more quickly and conveniently.
\end{abstract}

Keyword: Strategic Planning, Information System, Information Technology,Ward \& Peppard Method

Abstrak. Sekolah Dasar Islam (SD Islam) merupakan salah satu bagian dari lingkungan pendidikan tempat melaksanakan pembinaan dan pengembangan para siswa menuju tercapainya tujuan penyelenggaraan pendidikan. Oleh karena itu dalam penyelenggaraannya harus memiliki planning (rencana) yang terarah, tujuan yang jelas dan pelaksanaan yang dapat dipertanggungjawabkan. "Perencanaan Strategik Sistem Dan Teknologi Informasi didalam lingkungan Sekolah Dasar Islam Alfauzien Depok", karena dilihat dari kinerja dalam upaya pemanfaatan TI untuk menyelesaikan berbagai masalah dilingkungan sekolah belumlah optimal, contoh belum adanya pemanfaatan SI\&TI dalam pengolahan data yang khusus menangani masalah pengelolaan data secara otomatis dan terpusat, pemanfaatan SI\&TI untuk mengintegrasikan informasi lintas sekolah, Sekolah Dasar Islam Alfauzien Depok masih belum memiliki infrastruktur TI untuk mendukung pertukaran informasi yang terintegrasi antar sekolah di Depok, pemanfaatan SI\&TI strategik secara keseluruhan yang kurang menyebabkan sekolahsekolah di Depok belum merasakan fungsi SI\&TI secara strategik, seperti pengolahan data nilai dan penerimaan siswa baru untuk melayani masyarakat jauh lebih cepat dan nyaman.

Kata kunci : Perencanaan Strategik, Sistem Informasi, Teknologi Informasi, Metode Ward \& Peppard

\section{PENDAHULUAN}

Sekolah Dasar Islam Alfauzien Depok merupakan salah satu bagian dari lingkungan pendidikan tempat melaksanakan pembinaan dan pengembangan para siswa menuju tercapainya tujuan penyelenggaraan pendidikan nasional. Maka dalam penyelenggaraannya harus memiliki planning (rencana) yang terarah, tujuan yang jelas dan pelaksanaan yang dapat dipertanggung jawabkan. Serta adanya dukungan dan kebersamaan semua personal. Selain itu agar sasaran yang diharapkan dapat tercapai maka pembinaannya harus dilakukan secara terencana, terarah, bertahap, terpadu, terus menerus dan berkesinambungan. 
Oleh karena itu diperlukan suatu perencanaan strategik SI\&TI guna meningkatkan daya saing, efektivitas dan efisiensi organisasi, sehingga dapat mewujudkan visi, misi dan tujuan dari Sekolah Dasar Islam Alfauzien Depok, serta untuk mendukung strategik bisnis organisasi agar mampu mencapai tujuan bisnisnya dengan lebih cepat .

Kemampuan tersebut terkait langsung dengan bagaimana organisasi memilih strategik, aplikasi dan kebijakan organisasi yang tepat dengan berfokus pada Sistem Informasi dan Teknologi Informasi (SI\&TI). Dengan Perencanaan Strategik SI\&TI yang tepat, akan membantu organisasi dalam mengembangkan kompetensi yang intinya agar mampu bersaing dengan competitor-kompetitor lain.

\section{Perencanaan Strategik Sistem Informasi Dan Teknologi Informasi}

Perencanaan Strategik Sistem Informasi bagian dari proses perencanaan bisnis, dimana sebuah kebijakan informasi organisasi biasanya memberikan arahan baik bagi para pengelola maupun para pengguna informasi. Bagi para pengelola kebijakan informasi merupakan sebuah kerangka kerja yang berisi prinsip-prinsip organisasi yang berhubungan dengan informasi, penggunaannya dan pengelolaannya. Sedangkan dari perspektif pengguna, kebijakan informasi merupakan sebuah jaminan bahwa organisasi mempunyai komitmen untuk menyediakan informasi yang dibutuhkan (Henczel, 2001).

\section{Kerangka Pemikiran}

Kerangka pemikiran dalam penelitian ini mengenai perencanaan strategik SI\&TI yang akan menggunakan metode Ward dan Peppard dimana pendekatan metodologi ini dimulai dari kondisi investasi SI\&TI dimasa lalu yang kurang bermanfaat bagi tujuan bisnis organisasi dengan menangkap peluang bisnis, serta fenomena meningkatkan keunggulan kompetitif suatu organisasi karena mampu memanfaatkan SI\&TI dengan maksimal. Kurang bermanfaatnya investasi SI\&TI bagi organisasi disebabkan karena perencanaan strategik SI\&TI yang lebih fokus ke teknologi, bukan berdasarkan kebutuhan bisnis. Adapun skema metode Ward dan Peppard terlihat pada gambar 1 berikut :

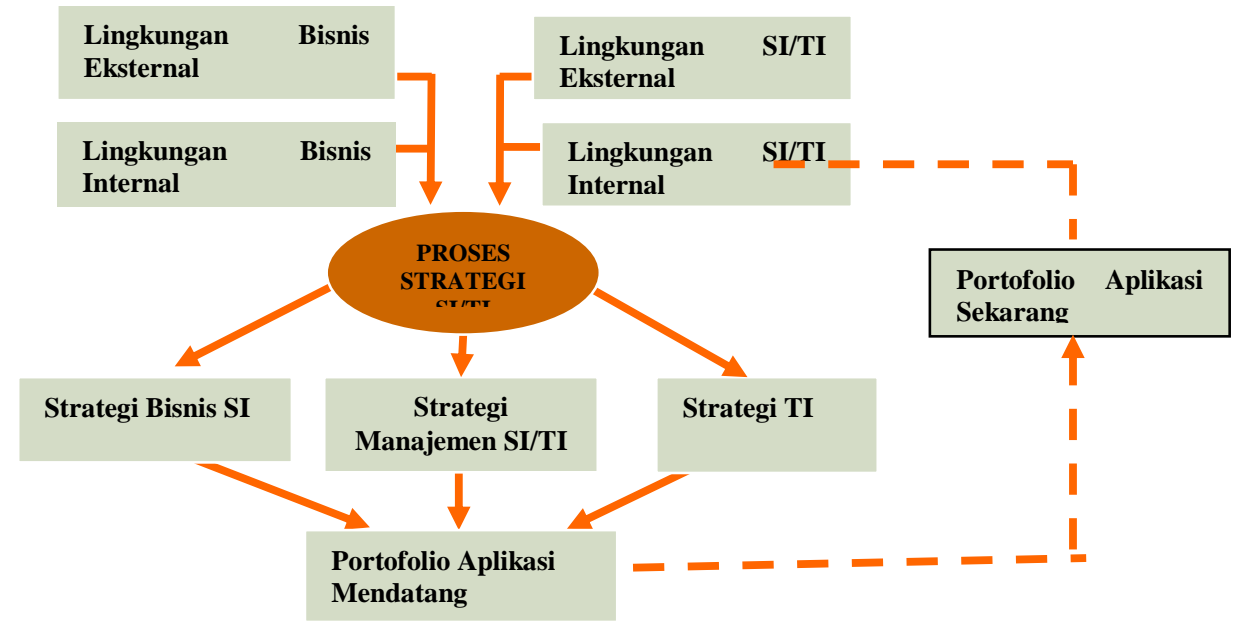

Gambar 1. Skema Metode Ward dan Peppard

Metodologi versi ini terdiri dari tahapan masukan dan tahapan keluaran (Ward dan Peppard, 2002). Tahapan masukan terdiri dari:

1. Analisis lingkungan bisnis internal, yang mencakup aspek-aspek strategik bisnis saat ini, sasaran, sumber daya, proses, serta budaya nilai-nilai bisnis organisasi.

2. Analisis lingkungan bisnis eksternal, yang mencakup aspek-aspek ekonomi, industri, dan iklim bersaing organisasi.

3. Analisis lingkungan SI\&TI internal, yang mencakup kondisi SI\&TI organisasi dari perspektif bisnis saat ini, bagaimana kematangannya (maturity), bagaimana kontribusi terhadap bisnis, keterampilan sumber daya manusia, sumber daya dan infrastruktur teknologi, termasuk juga bagaimana portofolio dari SI\&TI yang ada saat ini. 
4. Analisis lingkungan SI\&TI eksternal, yang mencakup tren teknologi dan peluang pemanfaatannya, serta penggunaan SI\&TI oleh kompetitor, pelanggan dan pemasok.

Sedangkan tahapan keluaran merupakan bagian yang dilakukan untuk menghasilkan suatu dokumen perencanaan strategik SI\&TI yang isinya terdiri dari:

1. Strategik SI, yang mencakup bagaimana setiap unit berfungsi dengan memanfaatkan SI\&TI untuk mencapai sasaran bisnis organisasi, membuat portofolio aplikasi dan gambaran arsitektur informasi.

2. Strategi TI, yang mencakup kebijakan dan strategik bagi pengelolaan teknologi dan sumber daya manusia.

3. Strategi Manajemen SI\&TI, yang mencakup elemen-elemen umum yang diterapkan melalui organisasi, untuk memastikan konsistensi penerapan kebijakan SI\&TI yang dibutuhkan.

Beberapa teknik/metode analisis yang digunakan dalam perencanaan strategik SI\&TI pada metodologi Ward dan Peppard, mencakup analisis Porter Five Forces, analisis PEST, analisis SWOT, analisis Value Chain, analisis Critical Success Factor's (CSF), analisis Balanced Scorecard, dan McFarlan's Strategic Grid.

\section{Analisis Porter Five Forces Model}

Porter mengusulkan bagaimana membuat strategi yang bertujuan menerapkan posisi yang menguntungkan dan mampu mengatasi permasalahan yang ditimbulkan oleh faktor-faktor tantangan yang dihadapi suatu perusahaan. Untuk berhasil dan berkembang dalam lingkungan yang demikian, perusahaan harus memahami interaksi yang terjadi dan implikasinya terutama kesempatan apa yang diraih untuk memiliki keunggulan kompetitif.

\section{Analisis PEST (Politik, Ekonomi, Sosial, Teknologi)}

Faktor-faktor dari analisis PEST ini adalah politik, ekonomi, sosial, dan teknologi. Tujuan dari analisis PEST adalah untuk mengidentifikasi kekuatan-kekuatan yang dapat mempunyai pengaruh besar terhadap organisasi, baik sekarang maupun di masa yang akan datang. Setiap organisasi tidak lepas dari lingkungan eksternal yang memberikan dampak pada cara organisasi berperilaku atau berkompetisi. Teknik ini digunakan untuk menganalisa lingkungan bisnis eksternal, agar dapat lebih memahami kondisi atau situasi bisnis organisasi.

Analisis SWOT (Strength, Weakness, Opportunity, Threat)

Analisis SWOT merupakan metode yang digunakan untuk menganalisa situasi kekuatan (strength) dan kelemahan (weakness) organisasi serta situasi ancaman (threat) dan peluang (opportunity) organisasi. Analisis ini didasarkan atas pemahaman tentang bagaimana membantu organisasi dalam memaksimalkan kekuatan yang dimiliki dan memanfaatkan peluang yang ada, serta meminimalkan kelemahan dan turut mengantisipasi ancaman yang timbul (Rangkuti,2009:19).

\section{Analisis Value Chain}

Porter memperkenalkan model rantai nilai untuk melihat aktivitas dalam perusahaan dan bagaimana interaksi antar aktivitas tersebut. Metode ini menguraikan perusahaan menjadi aktivitas-aktivitas yang relevan secara strategis untuk memahami perilaku biaya dan sumber difrensiasi yang sudah ada dan yang potensial. Aktifitas ini ada dalam rangkaian kerja berupa rantai yang akan memberikan nilai tambah pada proses pembuatan produk / jasa. Perusahaan bisa melihat yang menjadi unggulan dan kelemahan dari aktifitas yang dilakukan.

Model rantai nilai membagi dua kelompok aktifitas yaitu aktifitas primer dan aktifitas pendukung. Aktifitas primer, langsung terkait produk, terdiri dari:

1. Inbound logistic: aktifitas yang berhubungan dengan penerimaan, pemilahan, penyimpanan, dan penyebaran bahan kepada produk.

2. Operation: aktifitas yang berhubungan dengan perubahan bahan menjadi produk akhir yang akan diserahkan kepada pelanggan.

3. Outbound logistic: aktifitas yang berhubungan dengan pengumpulan, penyimpanan, dan penyebaran produk kepada pelanggan.

4. Marketing \& sales: aktifitas yang berhubungan dengan penyediaan sarana untuk mempengaruhi pembeli dan sarana bagi pelanggan untuk membeli produk atau mendapat 
layanan.

5. Services: aktifitas yang berhubungan dengan penyedia layanan untuk mempertahankan atau meningkatkan nilai manfaat produk / perbaikan.

\section{Analisis Critical Success Factors (CSFs)}

CSF dicetuskan John Rockart pada tahun 1981. Menurut pusat Riset Sistem Informasi (Center for Information System Research) definisi dari CSFs adalah hal-hal penting yang perlu mendapat perhatian lebih dalam menjamin keberhasilan suatu kegiatan organisasi. Merupakan metode untuk mengidentifikasi berapa aktivitas yang bersifat kritis yang harus dilakukan organisasi agar sukses.

Hasil analisis faktor sukses kritis, akan menggambarkan suatu pemetaan dari hal-hal yang harus dilakukan dengan benar, sehingga dapat memperbaiki kelemahan yang ada di organisasi sekaligus meningkatkan daya saing organisasi.

\section{Analisis Balanced Scorecard}

Balance Scorecard adalah alat untuk mengatur kinerja organisasi untuk pengembangan strategi organisasi itu sendiri. Dikembangkan oleh Hardvard Business School Academics Kaplan and Norton yang mendasari bahwa kesimbangan antara objectives dan measures sangat diperlukan. Hal ini dilakukan agar dapat dilakukan kontrol secara optimal dan terukur terhadap eksekusi strategik bisnis SI\&TI yang akan diambil. Balanced Scorecard mengkaji performa dari empat perspektif yang saling terhubung. Pertama adalah financial perspective, yaitu bagaimana pandangan stakeholder terhadap organisasi dalam kaitannya dengan perkembangan financial. Kedua adalah Internal Business Perspective yang mencakup permasalahan pemenuhan harapan karyawan dan partner. Ketiga adalah Costumer Perspective yang intinya adalah bagaimana pelanggan menerima kita dalam kaitannya dengan produk, pelayanan, hubungan dan nilai tambah. Keempat adalah Inovation and Learning Perspective, yaitu bagaimana melanjutkan untuk melakukan perbaikan dan membuat sesuatu yang baru lebih bernilai untuk stakeholders. Dari keempat perspektif di atas objectives dapat dirumuskan beserta dengan measures yang relevan untuk tiap objective-nya yang dapat disebut sebagai Key Performance Indikators (KPIs) yang akan membawa kepada suatu informasi yang diperlukan untuk mengukur performance.

\section{Analisis Portofolio McFarlan}

Analisis portofolio McFarlan yang dikembangkan oleh Warren McFarlan mengukur dampak strategi dari aplikasi saat ini dan proyek pengembangan aplikasi, digunakan untuk memetakan aplikasi SI berdasarkan kontribusinya. Portofolio aplikasi adalah berbagai sistem aplikasi yang dibutuhkan oleh berbagai fungsi didalam perusahaan untuk merealisasikan strategi dan tujuan bisnis organisasi. Model ini berfungsi untuk memetakan portofolio aplikasi pada kondisi sekarang atau pengharapan yang berperan strategik, berpotensi tinggi, kunci operasional maupun pendukung dilihat dari kontribusinya terhadap kesuksesan bisnis tergantung kontribusi yang diharapkan pada organisasi.

\section{METODE}

Pembahasan dalam permasalahan penelitian ini menggunakan metodologi Ward dan Peppard dengan mengadopsi dari buku Strategic Planning for Information System (Ward dan Peppard, 2002). Tahapan penelitian dibagi dalam beberapa tahapan seperti tahap seperti pada gambar 2 berikut : 


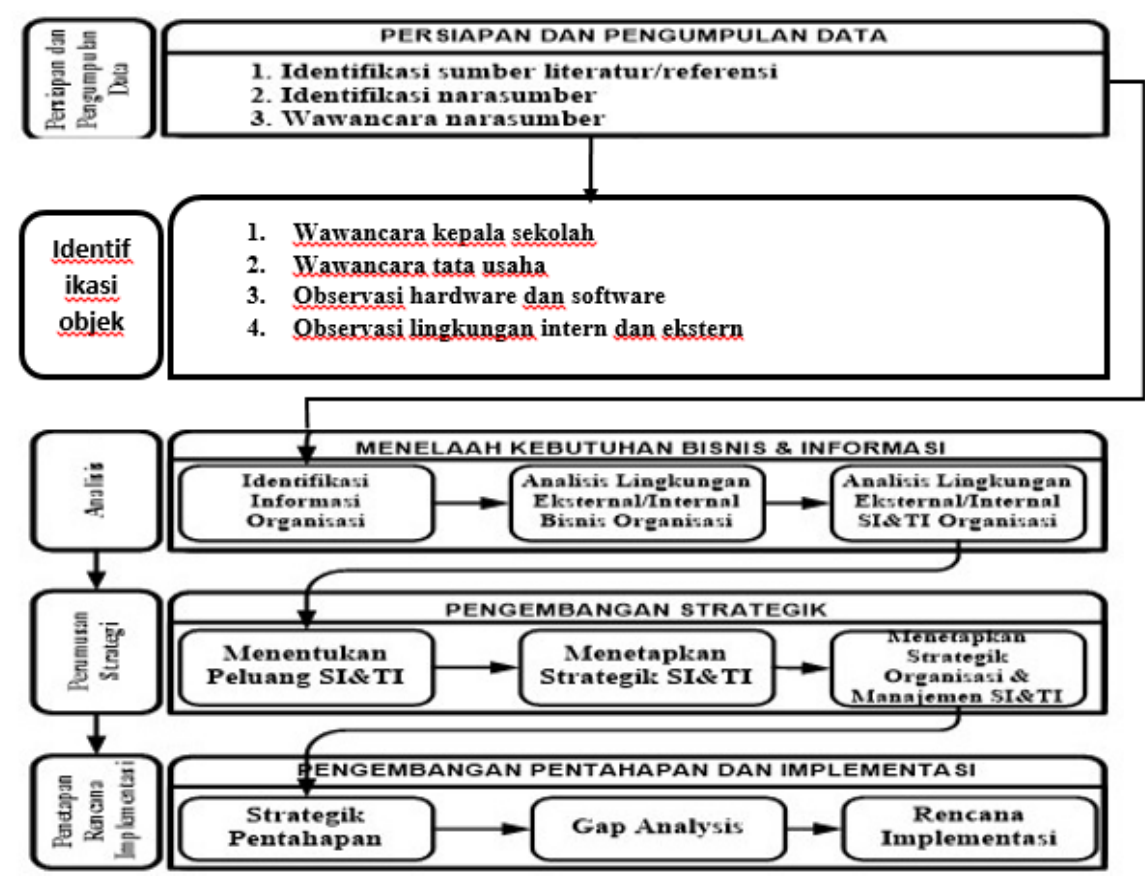

Gambar 2. Tahapan Metode Penelitian

\section{Tahapan Penelitian}

Secara umum tahapan-tahapan dalam melakukan penyusunan rencana strategik teknologi informasi tersebut terdiri dari empat tahapan yaitu:

1. Tahap Persiapan dan pengumpulan data

Melakukan identifikasi terhadap narasumber, mengumpulkan dan melakukan studi dokumen-dokumen sumber untuk mengambil data-data yang diperlukan.

2. Tahap Analisis

Data dan informasi yang diperoleh pada tahap sebelumnya akan dianalisis untuk mendapatkan kondisi saat ini dan analisis kebutuhan. Hasil analisis tersebut akan diuji silang terhadap perkembangan teknologi untuk mendapatkan rancangan secara arsitektur yang akan dimplementasikan. Tools yang akan digunakan dalam tahap analisis ini adalah PEST, Five Force, Value Chain, Balanced Scorecard, CSF, SWOT.

3. Tahap Perumusan Strategik

Berdasarkan rancangan arsitektur yang akan diimplementasikan, disusun strategi pengembangan teknologi informasi yang akan dilakukan. Sebelumnya dirumuskan dahulu parameter-parameter kunci yang diperlukan untuk merumuskan strategi tersebut.

4. Tahap Penetapan Rencana Implementasi

Menetapkan rencana implementasi dengan menyusun jadwal penerapan (roadmap) berdasarkan prioritas, kondisi dan kemampuan organisasi saat ini.

\section{HASIL DAN PEMBAHASAN}

Identifikasi narasumber dilakukan berdasarkan tugas pokok dan fungsi (tupoksi) dari narasumber untuk mengidentifikasi sumber-sumber informasi dan memperoleh data yang diperlukan untuk mendukung penelitian ini. Adapun narasumber berasal dari kepala sekolah, komite sekolah dan wakil kepala sekolah berdasarkan fungsi bidang masing-masing. Kemudian melakukan wawancara langsung yang dilakukan dalam rangka mendapatkan dan mengumpulkan data. Wawancara dilakukan kepada kepala Sekolah Dasar Islam Alfauzien Depok, komite sekolah, tata usaha sekolah dan wakil kepala sekolah dengan berdasarkan fungsi bidang masing-masing. 
Analisis menelaah kebutuhan bisnis dan informasi

Analisis kebutuhan bisnis dan informasi organisasi dilakukan untuk memahami secara mendalam tentang gambaran global organisasi seperti visi, misi, tujuan, dan strategi, analisis lingkungan eksternal/internal bisnis organisasi, analisis lingkungan eksternal/internal SI\&TI organisasi untuk menentukan dampak dan potensi SI\&TI terhadap pelaksanaan tugas pokok dan fungsi unit kerja (Pembantu kepala sekolah).

Analisis Lingkungan Bisnis Eksternal

Analisis lingkungan bisnis eksternal bertujuan untuk mengetahui dan mengidentifikasi berbagai kemungkinan peluang (opportunies) dan ancaman (treaths) sehingga menjadi faktorfaktor strategik eksternal atau EFAS (Eksternal Strategic Factors Analysis Summary) berdasarkan hasil analisis PEST (Politik Ekonomi Sosial Teknologi) dan analisis Five Forces.

Analisis PEST (Politik, Ekonomi, Sosial, Teknologi)

Faktor-faktor eksternal yang berpengaruh pada saat ini bagi Sekolah Dasar Islam Alfauzien Depok menggunakan analisis PEST meliputi aspek sebagai berikut :

Tabel 1. Analisis Lingkungan Bisnis Eksternal menggunakan PEST

\begin{tabular}{lllll}
\hline Kategori & Peluang & Ancaman & \\
\hline Politik & - Stabilitas politik dan keamanan yang & - Peraturan pemerintah melalui Badan \\
& kondusif & & Akreditasi Nasional (BAN) yang \\
& - UU No.2 Th. 1989 tentang Sistem & mengatur status akreditasi suatu \\
& Pendidikan Nasional dan pasal 31 & sekolah & \\
& UUD 1945 & & &
\end{tabular}

\begin{tabular}{|c|c|c|}
\hline Ekonomi & $\begin{array}{l}\text { - Bantuan } \\
\text { Pendidikan }\end{array}$ & $\begin{array}{l}\text { - Mayoritas pendapatan masyarakat } \\
\text { yang sedang } \\
\text { - Kenaikan harga dan inflasi }\end{array}$ \\
\hline Sosial & $\begin{array}{l}\text { - Dukungan Yayasan Al Azhar dan } \\
\text { masyarakat Depok } \\
\text { - Kesadaran masyarakat } \\
\text { pendidikan }\end{array}$ & $\begin{array}{l}\text { - Kebijakan kurikulum yang ketat dari } \\
\text { pemerintah } \\
\text { - Sekolah SD Islam swasta sejenis } \\
\text { yang ada di Depok }\end{array}$ \\
\hline Teknologi & $\begin{array}{l}\text { - Perkembangan teknologi internet yang } \\
\text { sudah umum dan cepat. } \\
\text { - Tersedianya berbagai teknologi open } \\
\text { source untuk membangun berbagai }\end{array}$ & $\begin{array}{l}\text { - Terbatasnya pemanfaatan teknologi } \\
\text { informasi di sekolah } \\
\text { - Aplikasi pelayanan sekolah masih } \\
\text { belum terintegrasi }\end{array}$ \\
\hline
\end{tabular}
aplikasi untuk web/desktop

\footnotetext{
Analisis Five Forces Model

Merupakan sebuah metode yang digunakan untuk mengidentifikasi ancaman-ancaman atau tekanan-tekanan kompetisi (Competitive Forces Model) dari kompetitor (lingkungan bisnis eksternal) seperti pada tabel berikut ini.

Tabel 2. Analisis Lingkungan Bisnis Eksternal menggunakan Five Forces pada Sekolah Dasar Islam Alfauzien Depok
} 


\begin{tabular}{|c|c|c|}
\hline Forces & Peluang & Ancaman \\
\hline Pendatang Baru & $\begin{array}{l}\text { - Masih sedikitnya SD Islam swasta } \\
\text { di Depok } \\
\text { - Sekolah Dasar Islam Alfauzien } \\
\text { Depok sudah dikenal masyarakat }\end{array}$ & $\begin{array}{l}\text {-Kebijakan } \\
\text { mempermudah pendirian sekolah } \\
\text { demi kemajuan pendidikan di } \\
\text { Depok }\end{array}$ \\
\hline
\end{tabular}

$\begin{array}{ll}\text { Pelanggan } & -\begin{array}{l}\text { Biaya iuran pendidikan yang } \\ \text { terjangkau }\end{array} \\ \text { Pesaing } & -\begin{array}{l}\text { Sekolah Dasar Islam Alfauzien } \\ \text { Depok sudah mempunyai banyak } \\ \text { prestasi dan pengalaman }\end{array}\end{array}$

Produk

Substitusi
- Bantuan dari Pemda melalui Dinas Pendidikan Daerah (BOS, BOM, BKMM)

Pemasok
- Pentingnya status akreditasi sebagai status sekolah terutama peringkat akreditasi A
-Pelanggan menginginkan kualitas mutu pendidikan yang tinggi

- Pesaing sudah menggunakan teknologi informasi untuk efisiensi proses pelayanan

- Sekolah Dasar Islam swasta sejenis lainnya yang ada di Depok dengan fasilitas dan mutu pendidikan yang sudah maju

- Kecepatan pelayanan sekolah yang cepat dan terintegrasi sesuai keinginan pelanggan

\section{Analisis Lingkungan Bisnis Internal Sekolah Dasar Islam Alfauzien Depok}

Analisis lingkungan bisnis internal meliputi identifikasi akan variabel-variabel kekuatan dan kelemahan dari aspek kelembagaan organisasi yang selanjutnya variabel-variabel tersebut akan digunakan kembali dalam analisis SWOT dan analisis menggunakan pengukuran kinerja Balanced Scorecard (BS), kemudian dikombinasikan dengan CSF.Sedangkan proses-proses yang biasa dijalankan di dalam penyelenggaraan organisasi dilakukan dengan pendekatan internal Value Chain.

\section{Analisis Balancad Scorecard dan CSF}

Analisis Balanced Scorecard $(B S)$ di sini digunakan untuk memetakan pengukuran tujuan, visi, misi ke dalam empat perspective yakni pembelajaran, internal bisnis proses, keuangan, dan pelanggan (stakeholder). Berdasarkan karakteristik atau perspective tersebut, maka dalam mencari tema dan indikator ikut dimodifikasi mengikuti visi dan misi dari organisasi. Sasaran strategi dari keempat perspektif BS Sekolah Dasar Islam Alfauzien Depok tersebut secara garis besar dijelaskan diuraikan pada tabel 3. berikut ini : 
Tabel 3. Sasaran Strategik Balanced Scorecard Sekolah Dasar Islam Alfauzien Depok

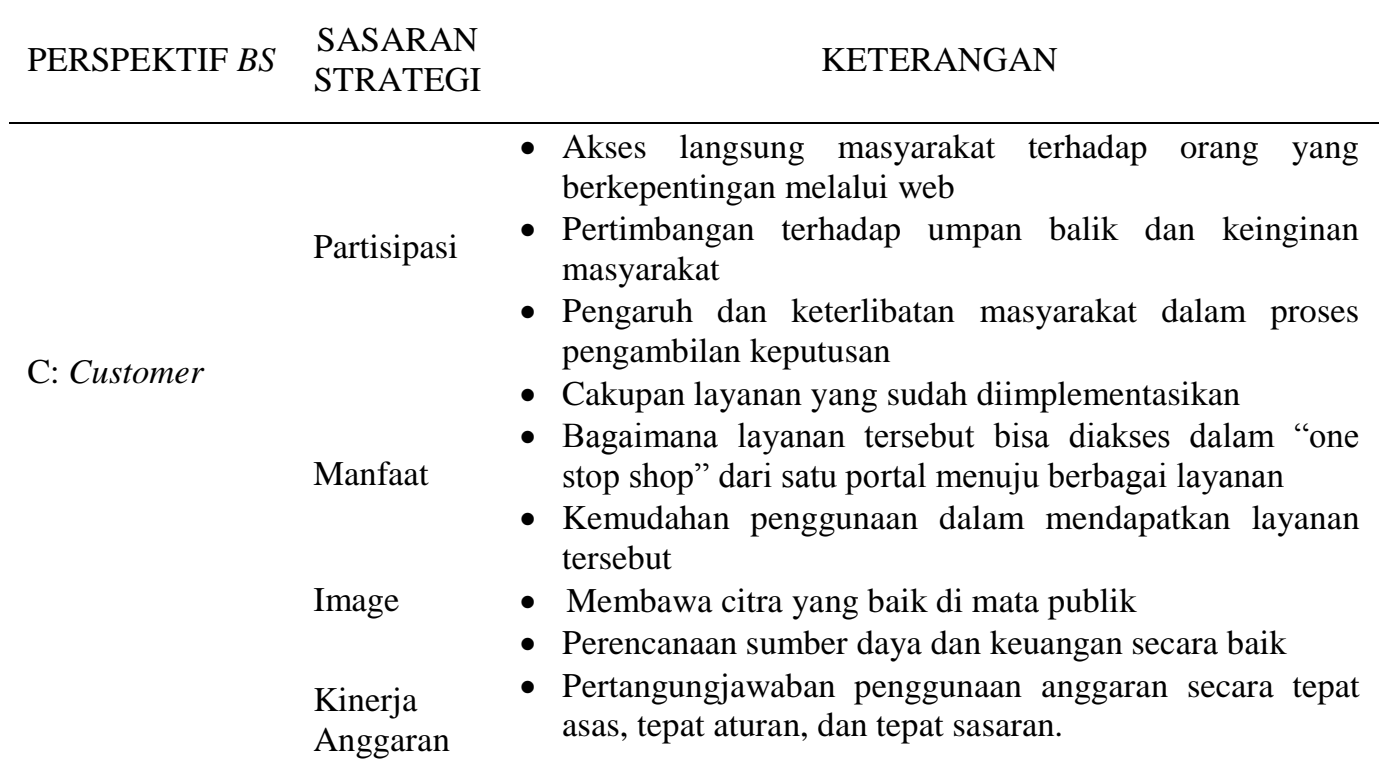

F: Financial

P: Proses Internal

L: Learning/ Pembelajaran

\section{Potensi Keuangan \\ Transparan si}

Efisiensi \& Efektivitas

Guru Informasi

Organisasi
- Kreativitas dalam meningkatkan sumber-sumber pendanaan/ keuangan dari berbagai kegiatan yang kreatif dan inovatif.

- Banyaknya informasi yang dikeluarkan sekolah dalam proses pengambilan keputusan (misalnya rapat POMG, laporan kerja, dan lain-lain)

- Informasi permohonan aplikasi beasiswa yang diajukan siswa. Apakah siswa misalnya bisa menanyakan dan mengetahui secara langsung apakah permohonan aplikasinya disetujui atau tidak.

- Berbagai proses yang teridentifikasi dalam value chain berlangsung efektif dan efisien.

- Keterlibatan dan motivasi dari guru

- Kualitas dan ruang lingkup pelatihan bagi para guru.

Ketersediaan arsitektur proses, aplikasi dan database yang bisa berjalan baik ketika dibutuhkan

Pemanfaatan platform teknologi informasi secara maksimal pada keseluruhan aspek

Kualitas kontrol dan review terhadap berbagai kebijakan dan regulasi.

\section{Analisis Lingkungan Bisnis Internal : Menggunakan SWOT}

Analisis SWOT digunakan untuk mengetahui kekuatan (Strength) dan kelemahan (Weakness) dari sumberdaya yang dimiliki organisasi serta peluang (Opportunities) dan ancaman (Threat) dari eksternal organisasi yang dihadapi. Analisis internal Sekolah Dasar Islam Alfauzien Depok dilakukan dengan menggunakan metode SWOT seperti diuraikan dalam Tabel 4. Analisis SWOT digunakan sebagai pertimbangan untuk menetapkan strategi pengembangan Sekolah Dasar Islam Alfauzien Depok. Berikut adalah analisis SWOT yang berpengaruh langsung terhadap lingkungan pendidikan Sekolah Dasar Islam Alfauzien Depok. 
Tabel 4. Analisis SWOT Pendidikan Sekolah Dasar Islam Alfauzien Depok

\begin{tabular}{ll}
\hline Kode & Kekuatan (Strength) \\
\hline S1 & $\begin{array}{l}\text { Sudah berdiri sejak lama } \\
\text { sehingga dikenal luas masyarakat } \\
\text { dan mempunyai pengalaman } \\
\text { serta prestasi }\end{array}$ \\
S2 & $\begin{array}{l}\text { Mempunyai status akreditasi } \\
\text { peringkat A yang setara dengan }\end{array}$ \\
& SD Negeri yang sejenis \\
S3 & $\begin{array}{l}\text { Jaringan hubungan kerjasama } \\
\text { yang baik dengan Yayasan Al }\end{array}$ \\
& $\begin{array}{l}\text { Fauzien, lembaga pemerintahan } \\
\text { baik nasional dan daerah, } \\
\text { lembaga non pemerintah serta } \\
\text { masyarakat }\end{array}$ \\
Kode & $\begin{array}{l}\text { PELUANG (Opportunities) } \\
\text { Mendapat bantuan melalui dinas } \\
\text { pendidikan daerah berupa BOS, }\end{array}$ \\
& BOM, BKMM \\
&
\end{tabular}

Kode Kelemahan (Weakness)

W1 Pengelolaan dan pemanfaatan SI\&TI

masih kurang dan belum memadai

W2 Kompetensi guru,staff dan karyawan dalam pemanfaatan SI\&TI masih kurang

W3 Kualitas dan profesionalisme tenaga sumber daya manusia masih rendah

\author{
Kode ANCAMAN (Threats) \\ T1 Meningkatnya persaingan memperoleh \\ siswa baru dan menciptakan lulusan \\ berkualitas di kota Depok
}

Kebijakan tentang kurikulum yang ketat dari pemerintah untuk mempertahankan kualitas pendidikan di Indonesia

T3

Dampak globalisasi dalam berbagai sektor, khususnya pendidikan yang menuntut kekuatan kompetisi yang tangguh di taraf nasional dan internasional

Berdasarkan identifikasi kekuatan (strength), kelemahan (weakness) yang dimiliki Sekolah Dasar Islam Alfauzien Depok, serta peluang (opportunities) dan ancaman (threats) yang dihadapi dalam pengembangan, maka perlu dirumuskan strategi pengembangan Sekolah Dasar Islam Alfauzien Depok, melalui: (1) mengembangkan kekuatan (strength) dan mengoptimalkan peluang (opportunities), (2)mengembangkan kekuatan (strength) untuk mengatasi ancaman (threats), (3) meminimalkan kelemahan (weakness) untuk memanfaatkan peluang (opportunities), dan (4) meminimalkan kelemahan (weakness) untuk menghindari ancaman (threats).

\section{Pengembangan Strategik SI\&TI}

Setelah melalui tahap analisis kebutuhan bisnis dan kebutuhan informasi pada uraian sebelumnya, maka selanjutnya akan ditentukan Strategik SI\&TI melalui penetapan solusi aplikasi dan strategi manajemen pengelolaan SI\&TI. Penentuan strategi ini diawali dengan merumuskan visi dan misi yang akan dilaksanakan sehingga dapat memberi dukungan bagi misi strategik Sekolah Dasar Islam Alfauzien Depok. Strategik SI\&TI menjelaskan penentuan portofolio aplikasi SI\&TI yang secara ideal akan dibangun beserta dukungan jaringan infrastrukturnya. Aspek-aspek pengelolaan teknologi informasi di lingkungan Sekolah Dasar Islam Alfauzien Depok merupakan bagian dari strategi manajemen.

\section{Menetapkan Strategik SI\&TI}

Prinsip dalam menetapkan penerapan strategik SI\&TI adalah untuk memberi pijakan tentang aplikasi apa saja (portofolio aplikasi) yang seharusnya dibangun dan dukungan infrastrukturnya berdasarkan tujuan dan strategi bisnis melalui suatu tindakan terukur dari 
sasaran strategik, pengukuran, indikator, $C S F$, kebutuhan informasi, dan yang terakhir adalah solusi SI\&TI-nya.

Pengembangan Pentahapan Dan Implementasi

Pada tahap pengembangan pentahapan dan implementasi ini, akan disusun perencanaan untuk mengimplementasikan strategik SI\&TI yang telah diterapkan. Masukan dari proses ini adalah konsolidasi semua temuan-temuan yang diperoleh pada tahapan sebelumnya. Keluaran dari tahapan ini adalah berupa gap analysis, roadmap (pentahapan) dan rencana jadwal migrasi implementasi SI\&TI.

Gap analysis

Gap analysis dilakukan untuk mengetahui apa saja yang dibutuhkan untuk memenuhi rencana yang sudah dibuat untuk masa mendatang. Tahapan pengembangan gap analysis dibuat berdasarkan atas solusi SI\&TI dan identifikasi kebutuhan informasi. Penentuan jadwal pengembangan SI\&TI berdasarkan skala prioritas yang telah ditentukan pada tabel 5. berikut ini.

Tabel 5. Penentuan Gap Analysis Berdasarkan Skala Prioritas

\begin{tabular}{|c|c|c|}
\hline Proses SI\&TI & $\begin{array}{l}\text { Kuadran Strategic } \\
\text { Grid }\end{array}$ & Business Value \\
\hline $\begin{array}{l}\text { Decision Support Systems } \\
\text { (Sistem Penunjang Keputusan) }\end{array}$ & High Potential & High \\
\hline Pembuatan Data Warehouse & High Potential & High \\
\hline $\begin{array}{l}\text { Pendidikan dan pelatihan sumber daya } \\
\text { manusia menuju penerapan pemanfaatan } \\
\text { SI\&TI di lingkungan sekolah. }\end{array}$ & Key Operational & Medium \\
\hline Knowledge Management & High Potential & Medium \\
\hline $\begin{array}{l}\text { Penyediaan sarana akses publik dalam } \\
\text { lingkungan sekolah antara lain dalam bentuk }\end{array}$ & Key Operational & Medium \\
\hline $\begin{array}{l}\text { Wi-fi internet gratis, dan lain-lain. } \\
\text { Sosialisasi keberadaan layanan informasi } \\
\text { elektronik, baik untuk publik maupun } \\
\text { penggunaan internal. }\end{array}$ & Key Operational & Medium \\
\hline
\end{tabular}

\section{Rencana Implementasi}

Tabel 6. Rencana Jadwal Migrasi Aplikasi SI\&TI Sekolah Dasar Islam Alfauzien Depok

\begin{tabular}{|c|c|c|c|c|}
\hline No & Rencana Kegiatan & $\begin{array}{l}\text { Tahun } \\
2017\end{array}$ & $\begin{array}{l}\text { Tahun } \\
2018\end{array}$ & Tahun 2019 \\
\hline 1 & $\begin{array}{l}\text { Decision Support Systems } \\
\text { (Sistem Penunjang Keputusan) }\end{array}$ & & & $\mathrm{X}$ \\
\hline 2 & $\begin{array}{l}\text { Pembuatan Data Base Management } \\
\text { System }\end{array}$ & & $\mathrm{X}$ & \\
\hline 3 & Pembuatan Data Warehouse & & $\mathrm{X}$ & \\
\hline 4 & $\begin{array}{l}\text { Pendidikan dan pelatihan sumber daya } \\
\text { manusia menuju penerapan pemanfaatan } \\
\text { SI\&TI di lingkungan sekolah. }\end{array}$ & $\mathrm{X}$ & $\mathrm{X}$ & \\
\hline 5 & Knowledge Management & & $\mathrm{X}$ & $\mathrm{X}$ \\
\hline 6 & $\begin{array}{l}\text { Penyediaan sarana akses publik dalam } \\
\text { lingkungan sekolah antara lain dalam } \\
\text { bentuk Wi-fi internet gratis, dan lain-lain. }\end{array}$ & $\mathrm{X}$ & $\mathrm{X}$ & \\
\hline 7 & $\begin{array}{l}\text { Sosialisasi keberadaan layanan informasi } \\
\text { elektronik, baik untuk publik maupun } \\
\text { penggunaan internal. }\end{array}$ & $\mathrm{X}$ & $\mathrm{X}$ & \\
\hline
\end{tabular}




\section{Strategik Pentahapan}

Berdasarkan pentahapan dalam penerapan pemanfaatan SI\&TI di Sekolah Dasar Islam

Alfauzien Depok, adapun hasil yang ingin dicapai pada tahapan ini adalah :

- Pembuatan DSS (Data Supporting System)

- Pembuatan DBMS (Data Base Management System)

- Pembuatan Data Warehouse

- Knowledge Management

- Pendidikan dan pelatihan sumber daya manusia menuju penerapan pemanfaatan SI\&TI di lingkungan sekolah.

- Penyediaan sarana akses publik dalam lingkungan sekolah antara lain dalam bentuk Wi-fi internet gratis, dan lain-lain.

- Sosialisasi keberadaan layanan informasi elektronik, baik untuk publik maupun penggunaan internal.

\section{PENUTUP}

\section{Simpulan}

1. Secara umum terlihat dalam pengelolaan SI\&TI yang harus ditangani berada pada tataran non-teknis yaitu belum adanya manajemen pengorganisasian personal yang khusus mempunyai kebijakan mengelola layanan SI\&TI sehingga dibutuhkan peran Wakil Kepala Sekolah sebagai pengambil kebijakan pengelolaan layana SI\&TI dengan mengkoordinasikan kegiatan pengembangan, pengoperasian, pemeliharaan, dan pengendalian sistem informasi serta infrastruktur jaringan komputer yang ada dalam lingkungan Sekolah Dasar Islam Alfauzien Depok.

2. Strategik SI dalam jangka pendek yang harus dilakukan untuk strategik bisnis Sekolah Dasar Islam Alfauzien Depok adalah dengan memperbaiki sistem pengkajian dan pengembangan kurikulum bagi siswa agar dapat lebih menambahkan kurikulum pendidikan berorientasi kepada teknologi informasi agar menghasilkan lulusan yang siap bersaing.

3. Berdasarkan Gap Analysis maka dibutuhkan suatu DSS (Decision Support Systems) atau sistem penunjang keputusan untuk dikembangkan dalam pengambilan kebijakan dan Datawarehouse untuk menyimpan serta memanfatkan data maupun informasi dari modulmodul aplikasi yang ada menjadi high potential.

\section{SARAN}

1. Pelaksanaan Rapat Kerja Tahunan (RKT) akan membantu dalam mengevaluasi dan meninjau hasil-hasil yang diperoleh dari proses penyusunan dan penerapan strategik SI\&TI tersebut.

2. Kepala Sekolah harus memperhatikan hasil dari gap analysis yang telah ditentukan dengan mengontrol implementasi dari perencanaan strategik SI\&TI tersebut.

\section{DAFTAR PUSTAKA}

E., McLean, E. \& Watherbe, J., 1996, Information Technology for Management, 2nd Edition, New York, USA : John Wiley \& Son.

Henczel, Susan. , 2001, The Information audit: a practical guide, Munchen: Saur.

Laudon, Kenneth C. and Laudon, Jane Price., , 2004, Management Information Systems: Managing the Digital Firm, 8th edition. New Jersey: Pearson Prentice Hall.

Martin, James, 1990, Information Engineering : Planning and Analysis, Prentice Hall International.

Oetomo, Budi, Sutedjo,D., 2002, Perencanaan \& Pembangunan sistem informasi, Yogyakarta :Penerbit ANDI.

Porter, M.E. 1998, Competitive Strategy: Techniques for Analysis Industries and Competitive, New York:The free Press. 
Rangkuti. F., 2009, Analisa SWOT teknik membedah kasus bisnis: Reorientasi Konsep Perencanaan Strategis untuk menghadapi abad 21. 16th Ed, Jakarta:Gramedia Pustaka Umum.

Turban, Efraim et. al., 2006, Information Technology for Management : Transforming Organizations in the Digital Economy, 5th ed. John Wiley \& Sons (Asia) Pte Ltd.

Tozer, E.E., 1996, Strategic IS/IT Planning, Professional Edition, Boston, USA : Betterworth-Heinemann.

Ward, John. and Joe Peppard, 2002, Strategic Planning for Information System 3nd ed England, John Wiley \& Sons.

Ward, J \& Griffiths, P., 1996, Strategic Planning for Information System, 2nd Edition, Chicester, USA:John Wiley \& Son.

Waterhouse, Price., 1996, System Management Methodology Overview/Baseline,Price Waterhouse World Firm Services BV Inc. 